Aguado, Teresa; Melero, Héctor S., \& Gil-Jaurena, Inés (2018). Espacios y prácticas de participación ciudadana. Propuestas educativas desde una mirada intercultural. RELIEVE, 24(2), art. M3. doi: http://doi.org/10.7203/relieve.24.2.13194

Revista ELectrónica de Investigación y EValuación Educativa

\section{RELIEVE}

ISSN: 1134-4032
e-Journal of Educational Research, Assessment and Evaluation

\title{
Espacios y prácticas de participación ciudadana. Propuestas educativas desde una mirada intercultural
} Spaces and practices of citizen participation. Educational proposals from an intercultural
perspective

\author{
Aguado, Teresa; Melero, Héctor S., \& Gil-Jaurena, Inés
}

Universidad Nacional de Educación a Distancia (España)

\begin{abstract}
The article presents the doctoral thesis research that has been developed in four spaces for civic participation in the city of Madrid for three years (2015/2017). We believe that citizenship is learned by exercising it and that spaces for participation are citizenship schools. The purpose of the study is to formulate educational proposals for the learning of active citizenship from the analysis of what happens in those spaces. The text is structured around these sections: 1) reflections and premises in relation to participation and education for citizenship; 2) direct background of the research and the continuities that are given in this work; 3) intercultural approach from which we understand citizen participation; 4) ethnographic study conducted through participant observation and interviews directed to 30 key informants. The four case studies and the analysis process are described through the categorical definition; 5) results organized into three major thematic blocks: diversity and complexity, relational vision and educational practices; 6) educational proposals derived from the results and aimed at both education professionals and people involved in spaces for citizen participation
\end{abstract}

Keywords: Intercultural education; citizen participation; intercultural education; qualitative research; educational research; learning participation, citizenship education.

\section{Resumen}

El artículo presenta la investigación de tesis doctoral que se ha desarrollado en cuatro espacios de participación ciudadana de la ciudad de Madrid durante tres años (2015/2017). Consideramos que la ciudadanía se aprende ejerciéndola y que los espacios de participación son escuelas de ciudadanía. La finalidad del estudio es formular propuestas educativas para el aprendizaje de la ciudadanía activa a partir del análisis de lo que sucede en dichos espacios. El texto se estructura en torno a estos apartados: 1) reflexiones y premisas en relación a la participación y la educación para la ciudadanía; 2) antecedentes directos de la investigación y las continuidades que se dan en este trabajo; 3) enfoque intercultural desde el que comprendemos la participación ciudadana; 4) estudio etnográfico realizado mediante observación participante y entrevistas dirigidas a 30 informantes clave. Se describen los cuatro casos de estudio y el proceso de análisis a través de la definición categorial; 5) resultados organizados en tres grandes bloques temáticos: diversidad y complejidad, visión relacional y prácticas educativas; 6) propuestas educativas derivadas de los resultados y dirigidas tanto a profesionales de la educación como a personas implicadas en los espacios de participación ciudadana.

Palabras clave: educación intercultural; participación ciudadana; educación intercultural educación; investigación cualitativa; investigación educativa; participación en el aprendizaje, educación para la ciudadanía

Fecha de recepción 2018 Octubre 22

Fecha de aprobación 2018 Diciembre 07

Fecha de publicación 2018 Diciembre 07 
Aguado, Teresa; Melero, Héctor S., \& Gil-Jaurena, Inés (2018). Espacios y prácticas de participación ciudadana. Propuestas educativas desde una mirada intercultural. RELIEVE, 24(2), art. M3. doi: http://doi.org/10.7203/relieve.24.2.13194

Desde finales del siglo XX el desinterés y la desconfianza de la ciudadanía en las instituciones democráticas, la llamada “desafección política”, ha provocado un extenso debate sobre la legitimidad de dichas instituciones donde la participación ciudadana, al ser considerada como uno de los requisitos fundamentales y constitutivos de la gobernabilidad en sociedades democráticas (Puelles \& Urzúa, 1996), se convierte en una de las principales líneas de actuación en procesos de reforma "desde arriba", como es el caso de la gobernanza europea. La construcción de una ciudadanía activa implicada en procesos de participación y transformación se presenta como un medio para el logro de la inclusión y la cohesión social en sociedades democráticas (Diario Oficial de las Comunidades Europeas, 2001).

En la mayor parte de los países europeos la formación para la ciudadanía ha supuesto la inclusión de la asignatura "Educación para la ciudadanía” en el curriculum oficial; también ha sido así en el caso español. No obstante, la evidencia acumulada muestra que el sistema escolar no es el mejor lugar para el aprendizaje de la ciudadanía y la participación (Conseil National d'évaluation du système scolaire, 2016). Aprender participación implica participar y aprender ciudadanía implica ejercerla. El discurso educativo centrado en el individuo y el niño no contribuye a promover la educación ciudadana. La fuerte estructura de la escuela no fomenta la construcción de espacios de participación y diálogo. Es preciso promover prácticas educativas dialógicas, reflexivas, socialmente integradoras (Veugelers, 2011) y generadas desde una mirada intercultural que reconoce la diversidad como normalidad y asume la equidad como compromiso de todo educador (Aguado, 2016).

Si entendemos dicha desafección política como una respuesta al déficit democrático sobre el déficit democrático en Europa son interesantes los trabajo de Enzensberger (2012) o Laval y Dardot (2017) - , podremos comprender los momentos de irrupción y de protesta de la ciudadanía en distintos lugares del mundo en los inicios del siglo XXI
(Castells, 2012) como procesos de resistencia a la pérdida de soberanía y poder de decisión, también llamada "des-democratización" (Estévez, 2013), consecuencia de la actual crisis de las democracias liberales (Castells, 2017). Un ejemplo de estos momentos es el $15 \mathrm{M}^{1}$ en España. Surge vinculado a la idea de profundización democrática, casi como un acto de defensa de una democracia percibida como amenazada por la falta de representatividad y de cauces de control que eviten decisiones políticas al margen de los intereses comunes (Manguijón \& Pac, 2012). Se produce una toma de conciencia de la posibilidad de generar nuevas formas de participación social desde una práctica ciudadana autónoma, una suerte de tránsito "de la representación a la apropiación" (Subirats, 2015). Se han reactivado y fortalecido distintos espacios de participación ciudadana de base, cuyas características se delimitan en torno a dos ejes relacionados: la justicia social entendida como la lucha frente a la exclusión y la desigualdad y la puesta en marcha de nuevas formas de gobernanza entendidas como el desarrollo de métodos de democracia directa y participativa (Pradel \& García, 2018).

En estos espacios las personas aprenden y ejercen la ciudadanía, participan y contribuyen a la transformación para una mayor justicia y cohesión sociales. Son auténticas escuelas de ciudadanía. Nos preguntamos acerca de cómo se ejerce y aprende en estos espacios, qué sucede en ellos, qué prácticas contribuyen a promover la

1 Movimiento 15 de Mayo también llamado Movimiento de los Indignados, surgido en España tras una manifestación de protesta por las reformas de corte neoliberal producidas tras la crisis económica del 2008. Tras dicha manifestación realizada el 15 de Mayo de 2011, se generó un movimiento ciudadano que ocupó el espacio público (varias plazas de las principales capitales del Estado Español) durante varios meses y que ha tenido distintas consecuencias en el espectro político nacional, tanto a nivel de movimiento ciudadano como de partidos políticos. Ver Pradel y García (2018) para los primeros y Rodríguez López (2016) para los segundos. Tambien Castells (2012), Mangiron y Pac (2012) o Taibo (2011). 
Aguado, Teresa; Melero, Héctor S., \& Gil-Jaurena, Inés (2018). Espacios y prácticas de participación ciudadana. Propuestas educativas desde una mirada intercultural. RELIEVE, 24(2), art. M3. doi: http://doi.org/10.7203/relieve.24.2.13194

participación y qué propuestas educativas emergen de este conocimiento.

En el caso concreto de la ciudad de Madrid, el cambio de gobierno municipal derivado de las elecciones de mayo de 2015 implicó una transformación del modelo asumido por anteriores responsables políticos ajenos o enfrentados a estos movimientos sociales. Este cambio llenó de esperanza e ilusión a muchos implicados en los mismos. No obstante, en poco tiempo las ilusiones se vieron frustradas en lo que se refiere a la capacidad transformadora de los nuevos responsables municipales. La única línea de transformación institucional es la que apunta a la extensión de los mecanismos de participación física y digital, aplicada principalmente en los llamados presupuestos participativos (Rodríguez López, 2016).

En este contexto se sitúa el estudio que aquí exponemos, producto de un trabajo de tesis doctoral (Melero, 2018), llevado a cabo en cuatro espacios de participación ciudadana de la ciudad de Madrid. Como ya hemos dicho, consideramos estos espacios como escuelas de ciudadanía en los que personas concretas con diversas experiencias, intereses y visiones ejercen y aprenden la ciudadanía de forma activa y crítica. La finalidad del mismo ha sido analizar, desde una mirada intercultural, lo que sucede en dichos espacios de participación con objeto de formular propuestas educativas para el aprendizaje de la ciudadanía activa desde un enfoque intercultural. Esta finalidad se ha concretado en varios objetivos formulados como cuestiones a responder:

- ¿Qué sucede en diversos espacios de participación ciudadana?

- ¿Qué prácticas pueden ser favorecedoras y cuales obstáculos para la práctica ciudadana?

- ¿Cómo se aprende y enseña el ejercicio ciudadano en los espacios de participación estudiados?

En este documento damos cuenta de las respuestas obtenidas a través del proceso de investigación desarrollado en cuatro momentos o etapas:

1) Revisar el marco teórico y los enfoques actuales sobre la ciudadanía y la participación, partiendo de las investigaciones previas $\mathrm{o}$ antecedentes directos del Grupo INTER de investigación en educación intercultural y desde el enfoque de intercultural en educación.

2) Identificar espacios y prácticas de participación ciudadana en consonancia con la delimitación conceptual anterior y los antecedentes directos.

3) Describir y comprender las prácticas de participación ciudadana que suceden en los espacios de participación ciudadana observados.

4) Realizar propuestas educativas para el aprendizaje de la ciudadanía desde un enfoque intercultural.

Estas propuestas finales se dirigen tanto a profesionales de la educación como a personas que participan en espacios ciudadanos variados.

\section{Antecedentes y continuidades}

Los antecedentes de este estudio los encontramos en trabajos realizados por miembros del Grupo INTER (www.uned.es/grupointer) (Aguado, Ballesteros, Mata, \& Sánchez-Melero, 2013; Gil-Jaurena, Ballesteros, Mata, \& SánchezMelero, 2016; Mata, 2011; Mata, Ballesteros, \& Padilla, 2013) fundamentados, entre otros aspectos, en el reconocimiento de que es preciso "investigar en profundidad acerca de cómo se construye la ciudadanía en los procesos educativos, entendidos en su dimensión más amplia, como procesos de aprendizaje continuo a lo largo de toda la vida." (Mata et al., pp. 51-52). Dos proyectos de investigación recientes de dicho grupo son especialmente significativos: "Aprendizaje de la ciudadanía activa. Discursos, experiencias y estrategias educativas” de 2009 a $2013^{2}$ y

2Plan Nacional de I+D; ref.: EDU2009-09195); I.P.

Teresa Aguado. Más información en

http://www2.uned.es/grupointer/aprendiz_ciudadania _activa.html 
Aguado, Teresa; Melero, Héctor S., \& Gil-Jaurena, Inés (2018). Espacios y prácticas de participación ciudadana. Propuestas educativas desde una mirada intercultural. RELIEVE, 24(2), art. M3. doi: http://doi.org/10.7203/relieve.24.2.13194

"Espacios de participación ciudadana: análisis y propuestas desde una perspectiva educativa" de 2012 a $2014^{3}$. Ambos con una finalidad compartida: la formulación de estrategias eficaces y propuestas educativas para el aprendizaje de la ciudadanía activa. El primero aporta evidencia en relación con las experiencias y discursos de personas que ejercen la participación en ámbitos diversos (educativos, medios de comunicación, sindicatos, asociaciones, e instituciones locales). El segundo estudio abordó un mapeo de espacios de participación en la ciudad de Madrid.

Se exponen en los siguientes apartados las continuidades teóricas y metodológicas que se han dado en estos trabajos previos, pues estimamos que pueden ayudar a comprender el estudio que aquí se presenta y a orientar futuros trabajos en esta línea.

\section{Continuidades teórico-conceptuales}

- Concepto de ciudadanía: La ciudadanía es percibida por las personas entrevistadas en los estudios anteriores como una categoría distante o estrecha y excluyente, por lo que ya desde el primer estudio se empezó a hablar de “ciudadanías" (Gil-Jaurena et al., 2016). Esto está directamente relacionado con la conceptualización de la ciudadanía como "práctica" frente a una ciudadanía como "estatus", puesto que "la idea cobra sentido cuando se percibe como práctica y se vincula a la propia experiencia y a los espacios más cercanos [...] con la clara conciencia de que hay distintas dimensiones en su práctica $y$, por tanto, ciudadanías plurales y diversas" (Gil-Jaurena et al., 2016, p. 292). La ciudadanía cómo práctica “implica necesariamente la relación con los demás, la construcción de colectividades con una finalidad” (Mata et al., 2013, p. 62).

En el plano teórico-conceptual, esto se relaciona claramente con el enfoque intercultural (Abdallah-Pretceille, 2001, 2006;

3 Plan de Promoción de la Investigación de la UNED; ref: 2012V/PUNED/0005; I.P. Inés Gil-Jaurena. Más información en

http://www2.uned.es/grupointer/espacios_participacio n.html
Aguado, 2009). Puesto que la ciudadanía, o más bien la(s) práctica(s) ciudadana(s), se construyen de manera relacional y situada, es decir, en contextos concretos de manera intersubjetiva, el enfoque intercultural se revela como un enfoque apropiado para su investigación, dado que también entiende la realidad de manera compleja y de construcción intersubjetiva mediante procesos de comunicación en los que se comparten, interpretan y construyen significados entre personas diversas.

- Elección del objeto de estudio: la práctica ciudadana: Los resultados de las investigaciones previas (Gil-Jaurena et al., 2016; Mata, 2011; Mata et al., 2013) nos han llevado a situar el foco del estudio en las prácticas que suceden en los espacios ciudadanos; es decir, ya no es tan importante definir el concepto de ciudadanía de manera teórica, no solo porque ese trabajo ya ha sido realizado a lo largo de los estudios anteriores, sino porque ha emergido la práctica ciudadana como concepto clave y que trasciende las limitaciones del concepto "ciudadanía" al poner el énfasis en la parte dinámica y cambiante del ejercicio ciudadano en sociedades democráticas. De nuevo, en coherencia con el enfoque intercultural, se da más importancia a lo dinámico de los procesos sociales.

- Foco en el aprendizaje de la ciudadanía: Una idea relevante tiene que ver con cómo se aprende el ejercicio ciudadano. "La ciudadanía se aprende en todo momento y lugar [...] por ello no podemos limitar el aprendizaje a contextos escolares" (Aguado et al., 2013, p. 39); hallazgo que da fuerza a la idea de situar el foco en el aprendizaje de la ciudadanía y no en la educación para la ciudadanía, tal y como venía sucediendo en los proyectos mencionados. La investigación que aquí se presenta entiende que primero hay que investigar cómo las personas involucradas en distintos espacios ciudadanos "aprenden" a ejercer su práctica ciudadana, antes de responder a la subsiguiente pregunta; "qué educación para qué ciudadanía” (Cabrera, 2002). A nivel teórico-conceptual, este foco evita que tengamos que entrar en 
Aguado, Teresa; Melero, Héctor S., \& Gil-Jaurena, Inés (2018). Espacios y prácticas de participación ciudadana. Propuestas educativas desde una mirada intercultural. RELIEVE, 24(2), art. M3. doi: http://doi.org/10.7203/relieve.24.2.13194

clasificaciones previas sobre las diversas propuestas de educación para la ciudadanía. Aunque podamos entender que dichas propuestas siempre deben estar en sinergia con planteamientos críticos y de justicia social (Carr, Pluim, \& Howard, 2014) y que deben ayudar a "adquirir los conocimientos y las habilidades necesarias para promover la justicia social en las comunidades, las naciones y el mundo" (Banks, 2008, p.137), la pretensión es investigar sobre ese objeto de estudio previo que es el "aprendizaje de la ciudadanía”.

- Dimensiones de la ciudadanía: Por último, en relación con las continuidades teóricoconceptuales, uno de los aspectos de las investigaciones previas que más ha influido en la tesis doctoral que enmarca este artículo son las dimensiones de la ciudadanía conceptualizadas y observadas a lo largo del primer estudio, ya que las mismas adjetivan y por lo tanto limitan el tipo de prácticas ciudadanas a observar, así como el tipo de espacios ciudadanos en los que realizar la investigación. Nos estamos refiriendo a la conceptualización de las prácticas ciudadanas como críticas, participativas $y$ transformadoras (Mata et al., 2013); conceptualización que además parece despertar interés y aceptación entre distintas personas implicadas en iniciativas ciudadanas, lo que se observó durante el desarrollo del segundo proyecto (Gil-Jaurena et al., 2013).

\section{Continuidades metodológico- procedimentales}

- Elección de la metodología de investigación: Todo lo dicho anteriormente también ha tenido su influencia a nivel metodológico-procedimental. Al concretar el foco de estudio, la selección de la metodología de investigación y de las prácticas y espacios ciudadanos a investigar se concretan de igual manera. Las aproximaciones cualitativas, etnográficas y participativas se presentan como las más adecuadas para la investigación desde el enfoque intercultural. Puesto que el enfoque intercultural también es coherente con los resultados obtenidos en los proyectos anteriores, al enfocar la "práctica ciudadana" (con su aspecto dinámico, relacional, experiencial, situado y diverso) como objeto de estudio también enfocamos la metodología de investigación. Además esto es coherente con la línea de investigación establecida desde los discursos y experiencias hasta las prácticas y espacios.

- Elección de los espacios donde realizar la investigación: Todo ello también se relaciona con otra de las continuidades más clara y de mayor influencia: Al enfocar el estudio sobre el aprendizaje de la ciudadanía (y no sobre la educación ciudadana) y tener como resultado previo el hecho de que "la ciudadanía se aprende, y se aprende a través de la práctica” (Gil-Jaurena et al., 2016, p. 294), o en otras palabras:

Una de las primeras ideas que emergen del análisis es que la ciudadanía crítica y participativa se aprende. Este aprendizaje es un proceso de construcción permanente que se realiza más por la vía informal que por la formal. Es decir, se aprende a ser ciudadano/a «siéndolo», poniendo en práctica la ciudadanía, participando en el mundo que nos rodea, implicándonos personalmente en los grupos, en los procesos colectivos y en la toma de decisiones (Mata et al., 2013, p. 60).

Lo que, junto a la idea de que este aprendizaje no se limita a los contextos escolares $\mathrm{y}$ al hecho de que entre los resultados se destacara que los movimientos sociales son punta de lanza del ejercicio ciudadano y, por tanto, modelos excepcionales para aprender la praxis ciudadana (Aguado et al., 2013), justifica y ha determinado la idea de investigar dicho aprendizaje ciudadano en los espacios donde los movimientos sociales ejercen su práctica ciudadana, razón de ser de esta investigación.

En cuanto a la selección de los casos de estudio, hay que destacar la influencia y continuidad con los trabajos anteriores (GilJaurena et al., 2016; Mata, 2011; Mata et al., 2013), pues se buscaron espacios en lo que se esperaba encontrar una práctica ciudadana crítica, participativa y transformadora y además se usó como herramienta para la selección el mapeo producido por varias 
Aguado, Teresa; Melero, Héctor S., \& Gil-Jaurena, Inés (2018). Espacios y prácticas de participación ciudadana. Propuestas educativas desde una mirada intercultural. RELIEVE, 24(2), art. M3. doi: http://doi.org/10.7203/relieve.24.2.13194

iniciativas ciudadanas, en relación con el segundo proyecto mencionado.

\section{Marco conceptual}

Como se ha señalado en la introducción, la construcción de sociedades democráticas exige el ejercicio y aprendizaje de la ciudadanía activa y participativa. Aprender participación implica participar y aprender ciudadanía implica ejercerla. El discurso educativo predominante centrado en el individuo y el niño no contribuye a promover la educación ciudadana. La fuerte estructura de la escuela no fomenta la construcción de espacios de participación y diálogo. Es preciso promover prácticas educativas dialógicas, reflexivas, socialmente integradoras (Veungelers, 2011) y generadas desde una mirada intercultural que reconoce la diversidad/complejidad como normalidad y asume la equidad como compromiso de todo educador (Aguado, 2016). Nos detenemos en delimitar el sentido de adoptar un enfoque intercultural en educación y en comprender qué significa participación ciudadana en el contexto de este estudio.

\section{Enfoque intercultural en educación}

La educación es una herramienta de liberación y emancipación, y sólo es liberadora cuando supone implicación, apropiación y la capacidad de agencia de las personas. Supone eliminar la relación dialéctica entre opresores y oprimidos, de conseguir transformar este mundo desigual y opresor en otro equitativo y libre (Freire, 1980, 2012). Así, los procesos educativos requieren de la implicación y la participación activa de cada persona en un espacio socioeducativo determinado.

Nos referimos al enfoque intercultural y no a la educación intercultural por estimar que intercultural no es un adjetivo sino una mirada con la que comprender la diversidad y la complejidad del mundo. Ponemos el foco en la cultura al reflexionar sobre la educación y asumimos la diversidad como normalidad. Nuestro compromiso ético y político es la equidad y la justicia social, valores propios de las sociedades democráticas (Aguado, 2009;
2016). El enfoque intercultural es práctica, comunicación y hermenéutica; es herramienta de análisis e interpretación y nos compromete en la práctica contextualizada en espacios educativos reales. En nuestro estudio, los espacios elegidos son espacios donde se llevan a cabo procesos de participación ciudadana asociados a movimientos sociales transformadores y críticos.

Los significados, las normas, las ideas, las creencias, se construyen, se expresan, se transmiten y se actualizan únicamente a través de las personas concretas. No existen objetos tales como "las culturas": lo que sí existe son seres humanos concretos creando, recreando y compartiendo en un medio cultural. La cultura esencializada funciona como una barrera que nos impide "ver" al otro y relacionarnos con él en clave de reciprocidad (Mata, 2011, p. 39).

El enfoque intercultural en educación es una praxis crítica comunicativa de coconstrucción y transformación sociocultural entre personas concretas, diversas, complejas y cambiantes (Melero, 2018).

Por tanto, el proyecto político de la interculturalidad, así enlazado con una pedagogía crítica, parte de la necesidad de implosionar epistémicamente en el conocimiento hegemónico y dominante; no buscar ser incluido en él (como el multiculturalismo neoliberal), sino intervenir en él, generando participación y provocando una contestación y cuestionamiento (Walsh, 2007, p. 33).

\section{Participación ciudadana}

La participación es la forma más pertinente de garantizar que la transformación social que perseguimos desde una mirada intercultural tenga lugar desde el reconocimiento de la diversidad de todos los implicados, tanto de sus características como de su posición y situación sociales.

Siempre que existan intervenciones del mundo real que puedan, en teoría, ser implementadas por diferentes sistemas de conocimiento, la elección concreta de la forma del conocimiento debe ser informada por el principio de precaución, el cual en el contexto de la ecología de saberes, debe ser 
Aguado, Teresa; Melero, Héctor S., \& Gil-Jaurena, Inés (2018). Espacios y prácticas de participación ciudadana. Propuestas educativas desde una mirada intercultural. RELIEVE, 24(2), art. M3. doi: http://doi.org/10.7203/relieve.24.2.13194

formulado como sigue: la preferencia debe ser dada a la forma de conocimiento que garantice el mayor nivel de participación a los grupos sociales involucrados en su diseño, ejecución y control, y en los beneficios de la intervención (Santos, 2009, p. 60).

La ciudadanía se contempla como categoría de análisis al entender que implica relaciones de horizontalidad y equidad. Preferimos hablar de participación ciudadana para subrayar su carácter dinámico y práctico. Distinguimos entre participación "desde arriba" cuando es promovida por las instituciones del estado y "desde abajo" cuando es la propia ciudadanía quien la genera. Es en estos espacios donde se ha situado el estudio que presentamos.

\section{Método}

El trabajo de investigación se ha realizado desde un acercamiento etnográfico en educación (Del Olmo, 2008; Goetz \& LeCompte, 1988; Sabirón, 2006) enmarcado en el enfoque intercultural, que entiende el mundo de manera compleja en continua construcción intersubjetiva o comunicativa entre distintos agentes (Abdallah-Pretceille, 2001, 2006; Aguado, 2009), de tal modo que la forma más adecuada de entender la realidad social es desde la comunicación directa con las distintas personas que participan en la construcción de significados y en los contextos en los que se produce dicha interacción comunicativa (AbdallahPretceille, 2001). Solo en el contexto social donde se procesa la información y comunicación es posible comprender el significado (Castells, 2009). El acercamiento etnográfico, basado en la participación durante periodos de larga duración (Del Olmo, 2008), pretende comprender la realidad social desde las propias personas que la construyen, buscar los significados compartidos que guían su comportamiento, así como las conductas individuales y colectivas que modifican dichos significados (Del Olmo \& Osuna, 2014).

\section{Trabajo de campo y casos de estudio}

En el trabajo de campo se han utilizado las principales herramientas de investigación de un trabajo etnográfico: la observación participante y la entrevista dirigida (Del Olmo, 2008). De forma complementaria, se han realizado análisis documentales sobre documentos producidos en los propios espacios en distintos formatos.

La selección de los casos de estudio para la observación participante se realizó con dos procesos consecutivos: a) selección intencional de casos significativos y b) acceso desde caso previo. A continuación se explica el proceso seguido y los casos seleccionados. La figura 1 también presenta un resumen.

a) Para la selección intencional se buscaban espacios ciudadanos de base (no promovidos desde la Administración) y de características críticas, participativas y transformadoras. Como herramienta de selección se utilizó un mapa de «iniciativas ciudadanas» de Madrid (http://bit.ly/losMadriles2015) elaborado desde una red de movimientos sociales en colaboración con el Ayuntamiento y en el que habíamos participado en sus primeros desarrollos (Gil-Jaurena, López-Ronda, \& Sánchez-Melero, 2015). Además, se pudo seleccionar un segundo caso siguiendo los mismos criterios de espacio ciudadano de basé con características críticas, participativas y transformadoras, pero a partir de informaciones llegadas por otras redes ligadas a los procesos barriales del $15 \mathrm{M}^{4}$. De esta forma se pretendía acceder a espacios de participación de distintas redes ciudadanas de Madrid. Los casos seleccionados fueron:

- Somos Barrio (SB): (http://bit.ly/SBarrio) iniciativa ciudadana de los barrios de Argüelles, Casa de Campo y Ciudad Universitaria (barrios de la zona norte de Madrid) cuya finalidad es la mejora de la

4 Tras la ocupación de las plazas centrales de las principales ciudades españolas durante los meses de verano de 2011, las distintas asambleas del movimiento $15 \mathrm{M}$ que se desarrollaron en esas espacios de cada ciudad fueron decidiendo, hacia el final de dicho verano, descentralizar su acción mediante la creación de distintas asambleas locales en barrios y municipios, independientes aunque conectadas entre sí. 
Aguado, Teresa; Melero, Héctor S., \& Gil-Jaurena, Inés (2018). Espacios y prácticas de participación ciudadana. Propuestas educativas desde una mirada intercultural. RELIEVE, 24(2), art. M3. doi: http://doi.org/10.7203/relieve.24.2.13194

calidad de vida en estos barrios mediante la participación ciudadana. En el momento del acceso llevan pocos meses de actividad como grupo, aunque la mayoría procede de agrupaciones anteriores originadas tras la descentralización barrial del movimiento 15M en Madrid. Durante la observación eran un grupo activo de unas 10-12 personas, mayoritariamente mujeres a partir de los 4045 años de edad.

- Espacio Vecinal Arganzuela (EVA): (http://bit.ly/EVArganzuela) son un grupo de personas y colectivos organizados alrededor de conseguir la cesión, por parte del Ayuntamiento, del Antiguo Mercado de Frutas y Verduras de Madrid $^{5}$ para la autogestión ciudadana, con la finalidad del desarrollo social y cultural a través de la participación directa de la ciudadanía. Durante la observación son un grupo amplio, con una fuerte presencia en redes sociales, muy fluido, por lo que es difícil de cuantificar dado que el número de personas presentes en las reuniones suele variar bastante, de más de 30 las más numerosas a 6 o 7 las de menor afluencia. A esto hay que añadir la alta participación a través de canales de comunicación digital, por lo que los perfiles son muy variados. La edad media rondaba los 35, aunque la franja oscilaba de 25 a 78 años.

b) Desde el Espacio Vecinal Arganzuela se tuvo la oportunidad de acceder a otros dos espacios de interés, lo que fue posible gracias a que los acercamientos cualitativos permiten un diseño flexible e interactivo en el que las fases de investigación se influyen continuamente unas a otras en un proceso de carácter continuo en el que el desarrollo de

5 Este edifico, considerado como patrimonio industrial del siglo $\mathrm{XX}$, ha pasado por distintos momentos de uso parcial y abandono según los intereses de los distintos gobiernos, hasta generar un proceso de defensa del mismo por parte de la ciudadanía (ver la web mercadolegazpi.org). Está ubicado en el distrito de Arganzuela (zona sur de la ciudad de Madrid) y es un edificio de gran tamaño, de amplias y espaciosas naves, lo que le convierte en un edificio poco habitual en este tipo de reclamaciones, que suelen ser de espacios más pequeños. cada fase influye y modifica a las demás (Rodríguez, Gil, \& García, 1996). El interés de estos dos nuevos espacios residía en dos aspectos diferentes: uno de los espacios respondía a los mismos criterios que guiaron la selección intencional, con el añadido de ser un medio de comunicación comunitario. El otro espacio de participación no respondía a dichos criterios, pues estaba promovido desde la Administración; sin embargo, era de interés como caso de contraste y por ser una respuesta del Ayuntamiento y la Junta de Distrito a las reivindicaciones de EVA. Por esta razón en la exposición de resultados se hace referencia de manera general a los tres espacios ciudadanos que cumplen todos los criterios, excepto si se hace referencia explícita a este último espacio institucional.

Los casos de acceso derivado desde caso previo fueron:

- Radio Arganzuela (RA): presentación del proyecto en una asamblea de EVA y un llamamiento por e-mail, distintas personas interesadas se apuntan a este proyecto de creación de una radio libre en el barrio. Es un proceso incipiente durante la observación, que se comunica fundamentalmente a través del correo electrónico $\mathrm{y}$, tras los primeros talleres presenciales de formación en radio, solo realiza reuniones presenciales de forma esporádica. Su composición también es fluida $y$ no se consolida durante la observación.

- Proceso Institucional Mercado Legazpi (ML): (la web ya no se encuentra operativa) fue desarrollado por el Ayuntamiento de Madrid a través de un grupo de arquitectos que hacía las veces de facilitadores durante los meses de Abril a Julio de 2016, con el objetivo declarado de «co-creación y cogestión» sobre el futuro del Mercado, aunque en la práctica es un proceso de consulta y deliberación no vinculante sobre el proyecto de rehabilitación que el Ayuntamiento tiene previsto realizar. El número de personas fue disminuyendo a lo largo de las sesiones. 
Aguado, Teresa; Melero, Héctor S., \& Gil-Jaurena, Inés (2018). Espacios y prácticas de participación ciudadana. Propuestas educativas desde una mirada intercultural. RELIEVE, 24(2), art. M3. doi: http://doi.org/10.7203/relieve.24.2.13194

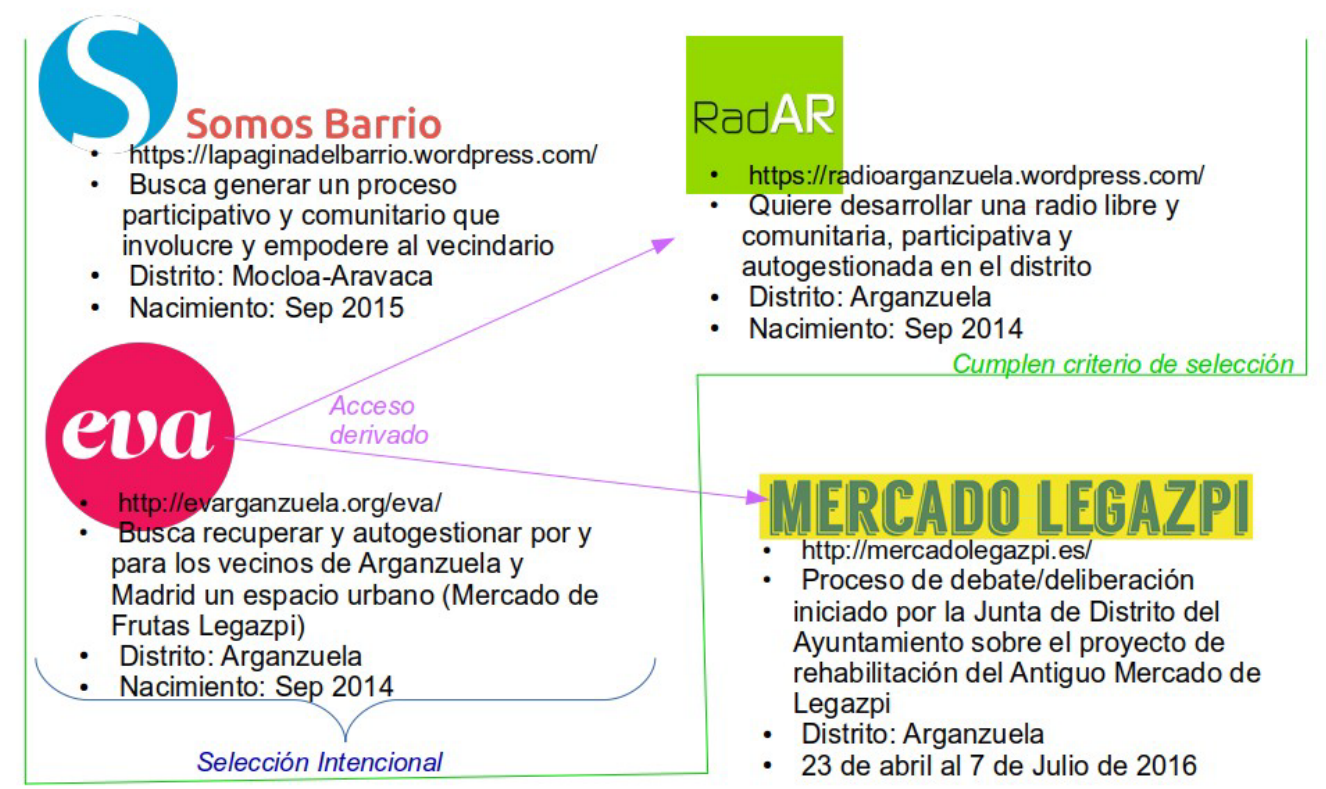

Figura 1: Casos de estudio agrupados en relación al proceso de selección

El trabajo de campo se desarrolló de Septiembre de 2015 a Abril de 2017, incluido el vagabundeo, selección, acceso y salida del campo; pero el grueso de la observación participante se realizó entre Diciembre de 2015 y Julio de 2016, recogida en el diario de campo. (Puede consultarse el gráfico del trabajo realizado en http://bit.ly/GraficoTCyDPs).

Además se realizaron 29 entrevistas a 30 informantes clave (una de ellas doble), seleccionados de manera intencional tratando de reflejar distintas formas de estar, comportarse, entender y mostrar la participación. Para ello se han seleccionado hombres y mujeres, personas de diferentes edades y con diferentes niveles de poder e influencia en el grupo. Las distribuciones varían según las características de cada espacio, y en algunas de las entrevistas se exploraron varios espacios. En total se entrevistaron 15 hombres y 15 mujeres con edades entre los 25 y los 78 años. (Pueden consultarse los datos de las entrevistas en http://bit.ly/DatEntrevistas).

\section{Análisis}

El proceso de análisis también es un proceso flexible y continuado en las investigaciones etnográficas (Goetz \& LeCompte, 1988), siendo la reducción de datos mediante la codificación y categorización la tarea representativa (Rodríguez et al., 1996). Para el proceso de análisis se utilizó soporte informático a través de Atlas-ti 7, para lo cual se preparó el material en documentos independientes de cada entrada del diario de campo (que en muchos casos incluye documentos incrustados elaborados por los propios espacios) y la transcripción de cada entrevista, con un total de 136 documentos. La primera reducción de datos fue excluir aquellos que no correspondían a observaciones directas en los espacios o a transcripciones de las entrevistas, quedando un total de 109 documentos analizados. Tras esto se realizaron dos procesos de vaciado consecutivos. El primero asistido digitalmente mediante los documentos elaborados por Atlas-ti para cada categoría de análisis. A partir de estos documentos se realizó el segundo vaciado mediante la selección de citas ilustrativas para cada parte de las definiciones finales de las categorías a las que se había llegado.

Estas categorías también fueron construidas a lo largo de la investigación, en diálogo entre el marco teórico, la recogida de datos y el análisis, en un proceso que podemos dividir en tres tiempos: un momento inicial en el que las categorías simplemente se formularon como ideas, pero sin una 
Aguado, Teresa; Melero, Héctor S., \& Gil-Jaurena, Inés (2018). Espacios y prácticas de participación ciudadana. Propuestas educativas desde una mirada intercultural. RELIEVE, 24(2), art. M3. doi: http://doi.org/10.7203/relieve.24.2.13194

definición cerrada; un momento intermedio, en que se hace un trabajo reflexivo que relaciona las categorías con bloques teóricos pero pensados como partes de un todo integrado; y un momento final en el que se elaboró una definición que trataba de enunciar las categorías definitivamente y de manera amplia tal y como reproducimos en la tabla 1.

Tabla 1: Categorías de análisis y sus definiciones a partir de Melero (2018)

\begin{tabular}{cl}
\hline Categoría & \multicolumn{1}{c}{ Definición } \\
\hline Diversidad & $\begin{array}{l}\text { Hace referencia a una visión compleja de la realidad, y es compleja porque es diversa, heterogénea. La } \\
\text { heterogeneidad es por tanto la norma y por ello es valorada positivamente. Educativamente hablamos de la } \\
\text { heterogeneidad como principio educativo. }\end{array}$
\end{tabular}

Cambio Hace referencia a la visión dinámica de la realidad. Por tanto la norma es que la realidad está en continuo cambio, y por ello es en sí mismo un valor, al igual que la flexibilidad, la capacidad de adaptación. Educativamente el cambio es tanto el fin como el motor/principio educativo.

Comunicación Hace referencia a una visión relacional de la realidad. Se entiende que la realidad es una red de conexiones y relaciones, que se valoran y fomentan, y donde el modo de relacionarnos cobra mucha importancia. La realidad está construida intersubjetivamente y por tanto se comparten y construyen significados y sentidos compartidos. El diálogo se convierte en una herramienta fundamental para la puesta en común y la coordinación de acciones entre los distintos agentes, por lo que se deben poner en marcha estrategias de comunicación que permitan que las decisiones se tomen a través del intercambio de argumentos razonados en posiciones de igualdad y en busca de consensos. Educativamente hablaríamos de la educación como comunicación y del diálogo como principio educativo.

Crítica El "Criticismo" hace referencia al cuestionamiento de las situaciones de desigualdad y las relaciones de (pensamiento/ac poder. Cuando hablamos de "Pensamiento crítico" nos referimos a las reflexiones, debates e ideas que se titud) comparten en esta dirección, mientras que la "Actitud crítica” hace referencia a conductas y acciones que buscan construir relaciones horizontales basadas en la libre asociación. A nivel educativo hablaríamos del aprendizaje democrático por el cuestionamiento y ruptura con lo existente.

Participación Participar es incidir en la vida pública, formar parte de las decisiones que nos influyen como miembros de un colectivo o comunidad así como de las acciones que de estas se derivan. Buscar la participación es tratar de tomar las decisiones colectivamente entre el mayor número de agentes posible y llevarlas a cabo de manera cooperativa. Por ello participar tiene un claro componente activo y colectivo. Por tanto a nivel educativo hablaríamos del aprendizaje ciudadano como acto experiencial, práctico, desde la acción y la colaboración.

\section{Niveles de Participación}

En relación con la categoría «participación». Tradicionalmente los niveles hacen referencia a una clasificación de la participación que la ordena según la capacidad de influencia de la ciudadanía en la toma de decisiones. Distinguimos cuatro niveles en donde los dos inferiores se relacionan con la información, que siendo imprescindibles para la toma de decisiones no son suficientes ni garantizan capacidad de influencia, mientras que los dos superiores ya contemplan capacidad de influencia en la decisión final. 1. Información: la comunicación es unidireccional, la ciudadanía es un mero receptor de la información. 2. Consulta: La comunicación es bidireccional, la ciudadanía es escuchada pero no tiene capacidad de influencia en la decisión. 3. Implicación: La ciudadanía tiene una capacidad de influencia limitada en la decisión, puede debatir y decidir algunos aspectos, pero no tiene pleno control y muchas decisiones que determinan el resultado final están fuera de su influencia. 4: Autogestión: La ciudadanía tiene influencia plena sobre todas las decisiones que se toman.

Transformación La acción ciudadana persigue el cambio social y/o personal, entendido como objetivo y como proceso de (objetivo creación de un mundo mejor. Por ello la direccionalidad o finalidad del cambio que se persigue es la /proceso) justicia social. A nivel educativo hablaríamos del aprendizaje ciudadano como creación y experimentación.

Holismo En referencia a una visión amplia y compleja de la educación. Una visión educativa holística contempla educativo resultados educativos intencionales y/o incidenciales, de acciones educativas planificadas y/o informales $\mathrm{y}$ que por tanto puede suceder y suceden a lo largo de toda la vida, en distintos espacios y momentos y por distintos medios y canales. 
Aguado, Teresa; Melero, Héctor S., \& Gil-Jaurena, Inés (2018). Espacios y prácticas de participación ciudadana. Propuestas educativas desde una mirada intercultural. RELIEVE, 24(2), art. M3. doi: http://doi.org/10.7203/relieve.24.2.13194

\section{Resultados}

Los resultados se exponen en relación con tres dimensiones fundamentales derivadas del análisis realizado a partir del marco teórico y la construcción de los datos: diversidad y complejidad, visión relacional de la realidad y prácticas educativas, que se relacionarían con las categorías diversidad, cambio, comunicación y holismo educativo respectivamente.

\section{a) Complejidad e intersubjetividad}

El primer aspecto a señalar es que nos encontramos con una visión compleja de la realidad: las personas que participan en estos espacios, en distintos grados, tienen claro que el mundo social es complejo:

\begin{abstract}
"Y luego como ente, que me gusta a mi cuando se utiliza la palabra «ente», es hipercomplejo, si ya un ser humano es complejo, todo este tipo de cosas el EVA, 15M y mogollón de historias más son súper, súper, súper complejas [...] yo lo definiría así como un ente complejo que, o lo pondría así como un conducto de ventilación con ojos con un montón de tuberías y de cada tubería pues sale un chorro de aire de un color diferente, $y$ entonces dependiendo de cómo va el aire pues a lo mejor ese día te sale de un color, te sale azul cielo o verde esperanza, o el otro día te sale negro, negro, negro que no se ve nada pero así” Entrevista:26ð̂̉(EVA).
\end{abstract}

Vemos en la cita anterior que esta complejidad se relaciona con la diversidad de los "distintos chorros de aire" y con los cambios que se van produciendo "ese día". Estos dos elementos, diversidad y cambio, se relacionan en muchas ocasiones o se unen para describir la complejidad del mundo. El mundo social es complejo porque está en continuo cambio y porque está integrado por personas diversas, es heterogéneo y dinámico.

Esta complejidad supone la existencia de distintas tensiones, pero cabe decir que estas tensiones no se resuelven eliminando la complejidad, sino afrontándolas según van surgiendo en cada momento. La diversidad y el cambio son valorados positivamente, por lo que no hay que renunciar a ellos sino potenciarlos. Encontramos en todas las entrevistas esta valoración positiva de la diversidad y el cambio:

"La mayoría de las personas que en principio montamos Somos Barrio, ahora, afortunadamente, hay un grupo de gente más amplio y no todo el mundo viene con el mismo proceso" Entrevista:60ㅇ( $\mathrm{SB}$ ).

Por todo ello, dado que el mundo es complejo por su gran diversidad y su continuo cambio, y esta diversidad y dinamismo es un hecho positivo, entonces la flexibilidad y la apertura son cualidades deseables, tanto para potenciar la mayor pluralidad posible como para aprovechar el cambio de manera favorable.

A lo largo del trabajo de campo esta idea ha sido repetida por infinidad de agentes. Destacan los encuentros realizados entre el 28 y el 30 de Enero de 2016, a los que asistieron personas de distintos espacios de participación; el día 28 EVA organizó una especie de grupo de discusión en el que participaron personas de "Tabacalera”, "Esto es una Plaza" y el "Campo de la Cebada"6, y el día 30 un encuentro de espacios ciudadanos organizado por la aun flamante Red de Espacios Ciudadanos (REC), en los que participaron diversos espacios de participación y autogestión de toda España ${ }^{7}$. En ambos días varias personas incidieron sobre esta idea de la necesidad de flexibilidad y apertura:

“Habla (nombre ${ }^{\Uparrow}$ ) del Campo de la Cebada para recalcar el tema del clima abierto, la red tiene que ser abierta y diversa, hay que construir desde la diferencia y la diversidad, cada vez más distintos y aun así podemos trabajar juntos” Diario:30Ene2016(EVA).

6 Espacios de participación de la ciudad de Madrid, más información en: Tabacalera (http://latabacalera.net/), Esto es una Plaza (http://estaesunaplaza.blogspot.com.es/), "El campo de la Cebada” cerró a finales de 2017 su web está en suspenso (http://elcampodecebada.org/)

7 Puede verse información en http://www.espaciosciudadanos.org/la-red/ donde además hay un video con la puesta en común final. 
Aguado, Teresa; Melero, Héctor S., \& Gil-Jaurena, Inés (2018). Espacios y prácticas de participación ciudadana. Propuestas educativas desde una mirada intercultural. RELIEVE, 24(2), art. M3. doi: http://doi.org/10.7203/relieve.24.2.13194

"Y tener en cuenta que la idea inicial que tiene cada persona no es la que va a salir al final, sino otra, por lo que es necesario trabajar con flexibilidad y apertura, para que se hagan las cosas y no se queden en palabras hay que probar sin miedo pero con control" Diario:28Ene2016(EVA).

Esto supone, como se anticipaba en la última cita, apreciar la idea de "probar" a través de la acción, valorar la capacidad de improvisar y experimentar como fuentes de aprendizaje individual $\mathrm{y}$ colectivo $\mathrm{y}$, por tanto, de transformación:

"Porque siempre dejamos todo a la improvisación (risas) si te das cuenta, cuando hacemos alguna cosa, hay un margen ahí. $Y$ al final todo sale bien, o sea, y eso es lo bueno el poder reaccionar, o sea, el tener la capacidad de reaccionar, de adecuarnos a las circunstancias en cada momento y salir al paso a cualquier dificultad que tengamos, y es que eso es bueno, porque eso, nos ayuda como personas, nos ayuda como colectivo y nos ayuda para lo que tenga que venir" Entrevista:38 + (EVA).

"Hay proyectos que ya pueden empezar y que tienen esa potencialidad de hacer barrio, que es de lo que se trata, si lo que queremos es cambiar las reglas del juego, pues tiene que ser desde un espacio donde sea un laboratorio de cierto modo, y que tampoco nosotros sabemos dónde vamos a llegar, eso es lo bonito también, entonces mucha generosidad para que la potencialidad de los demás esté ahí" Entrevista:60 (EVA|RadAr).

Además la capacidad de adaptación, de estar preparado para el cambio, y no solo preparado, sino buscándolo de manera activa, permite estar atento para aprovechar las oportunidades que puedan ir surgiendo.

Así mismo, tener esta concepción dinámica del mundo también permite una visión de continuidad a la vez que de transformación; conecta en cierta forma el pasado del que se pueden extraer aprendizajes para el futuro que se persigue mediante las acciones en el presente. Por ejemplo en la presentación del 30 de Enero se recoge que «Plantean REC como una conversación abierta que mira hacia adelante y también hacia atrás donde se reconocen en una tradición de
generaciones Diario:30Ene2016(EVA). También otro informante dice entender EVA como un cambio de paradigma con el modelo anterior de reivindicación y protesta propio de las asociaciones vecinales, pasando con ello de la protesta a la propuesta. Pero a la vez asegura que la idea de "espacio vecinal" es una forma de homenajear esa tradición.

Así mismo hay un interés en visibilizar y valorar los distintos roles o funciones que se ejercen y que no siempre se visibilizan o se tienen en cuenta por ser diferentes a lo que suele catalogarse como tales. Así, recogía una anécdota de un vecino del Campo de la Cebada que no suele bajar a asambleas y actividades, pero llama siempre que considera que el volumen puede molestar al vecindario; visibilizar este rol les permitía evitar conflictos con su comunidad cercana:

"También se comenta la anécdota de un vecino del campo que siempre llama cuando las actividades que se hacen superan un volumen de molestia, no baja a asambleas ni nada, pero se sabe que «si (nombre ${ }^{\hat{O}}$ ) te llama hay que bajar el volumen» y a partir de esta anécdota se habla de este tipo de roles, que no se suelen tener en cuanta y que pueden ser importantes, roles autoimpuestos" Diario:28Ene2016(EVA).

Por otra parte, durante toda la observación, se observó en el diario de campo que hubo una pareja dicotomizada de categorías que fue especialmente importante, esta es “ciudadanía-institución”. En la mayoría de las observaciones desarrolladas en los espacios, cuando algún representante municipal estaba presente, se advertía una polarización de las posiciones y una centralidad de la figura municipal que desplazaba el discurso de la ciudadanía hacia la reivindicación y la queja. Resulta pertinente resaltar el uso de estas categorías y sus consecuencias en cuanto a la “eliminación” de la diversidad y pluralidad. Por ejemplo, esta visión dicotómica genera visiones especulares, así estos espacios pretenden ser diversos, plurales, contrapartes e interlocutores de "una" institución que parece percibirse de manera homogénea. 
Aguado, Teresa; Melero, Héctor S., \& Gil-Jaurena, Inés (2018). Espacios y prácticas de participación ciudadana. Propuestas educativas desde una mirada intercultural. RELIEVE, 24(2), art. M3. doi: http://doi.org/10.7203/relieve.24.2.13194

"De alguna manera, nos construyamos como sujeto activo en este proceso, también para que la administración tenga una contraparte, tenga un interlocutor, tenga un referente, y que ese referente, pues bueno, sea el más diversorico-plural posible” Entrevista:469(SB).

\section{b) Visión relacional de la realidad: colectividad, intersubjetividad y diálogo}

Una visión relacional implica una visión comunicativa de la realidad, esto supone que hay varios elementos entremezclados e interconectados que podemos agrupar en tres grandes bloques: por un lado, las prácticas y discursos enfocados en las relaciones con el resto, en las redes, la comunidad, lo colectivo; por otro, aquello que entronca con la construcción colectiva de la realidad, la construcción intersubjetiva de significados; y por último, la comunicación como forma de coordinación de acciones colectivas, el diálogo como herramienta de toma de decisiones.

Existe en estos espacios una centralidad de lo relacional que tiene distintas consecuencias; por un lado hay una insistencia continua en crear redes, fomentar las conexiones e implicar al mayor número de agentes posible en las acciones, es decir, es importante darse a conocer al vecindario y a otros agentes para conectar y realizar acciones conjuntas:

"Desde que nos juntamos, pues hemos abierto lo que son los debates de presentarnos a los barrios como plataforma para que, la gente vaya oyendo de nosotros, vaya sabiendo un poco cual es nuestro objetivo" Entrevista:46 9 (SB).

La centralidad en lo relacional que da una gran importancia a lo colectivo no supone, sin embargo, una eliminación de la diversidad individual, como se desprende de lo expuesto en el apartado anterior. La crítica existente hacia las acciones que responden solo a intereses individuales no se basa en la inexistencia de esos intereses o su "sujeción" a unos intereses generales, sino que es una crítica a la falta de preocupación por la construcción colectiva, a la carencia del intento o pretensión por combinar los intereses individuales de distintas personas convirtiéndolos así en intereses colectivos. Se menciona por tanto la idea de "equilibrio" o conexión entre lo individual y lo colectivo, a esta conexión responde la centralidad de lo relacional y el interés en la acción colectiva:

"Que sea un colectivo, no que sea, pero un colectivo, pero, para mí es importante también, tener en cuenta que cada uno tiene un, un individuo y cada uno tiene sus ideas y esos tampoco tienen que eso, o sea para mí sería importante buscar el equilibrio entre el individuo y el colectivo y yo creo que se puede hacer, pero hay que hablarlo mucho"

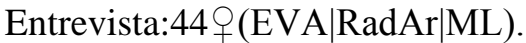

Otro aspecto fundamental cuando se habla de la visión relacional y comunicativa de la realidad es la idea de que los significados con los que interpretamos la realidad se construyen de manera intersubjetiva, es decir, es la propia relación comunicativa la que genera los marcos de interpretación bajo los que entendemos y explicamos el mundo. Se ha podido observar este proceso en distintas ocasiones durante el trabajo de campo, algunas de las cuales eran intencionales y otras no, aunque existe en los espacios observados una consciencia clara de la importancia de trasmitir ideas y crear "sentidos comunes" para transformar la realidad. Hay una consciencia de que la lucha por la igualdad y la justicia social, la lucha por el cambio social, debe jugarse también en este plano discursivo. Esta ha sido otra idea recurrente en muchas de las conversaciones y observaciones a lo largo de la investigación. De hecho, "Somos Barrio" organizó unas jornadas de debate y encuentro temático sobre "cultura y participación" en las que se transmitió esta noción de transformar el "sentido común” para transformar el mundo. Concretamente fue la ponente Montserrat Galcerán (filósofa y concejala de distrito en ese momento) quien insistió sobre este tema. Se reproducen a continuación las ideas recogidas en el Diario de campo durante su intervención:

"La importancia del campo cultural, ya que es un campo en que los conflictos sociales reverberan, porque justamente en el campo 
Aguado, Teresa; Melero, Héctor S., \& Gil-Jaurena, Inés (2018). Espacios y prácticas de participación ciudadana. Propuestas educativas desde una mirada intercultural. RELIEVE, 24(2), art. M3. doi: http://doi.org/10.7203/relieve.24.2.13194

cultural se construye el imaginario colectivo por lo que no es un campo baladí, hace referencia a la guerra cultural aunque no llega a usar este término. [...] Aquí se crean los significados que se dan al sentido común, es decir a los sentidos previos, los prejuicios o los presupuestos que construyen el discurso común y que se toman cómo verdades universales (esencialización), hasta el punto que cuando alguien cuestiona alguna de estas premisas se considera que no está en su sano juicio (pone el ejemplo de la polémica con el vestuario del mago de Navidad) Esto produce un choque cuando llega otra persona que tiene otros sentidos comunes y que cuestiona los establecidos, ya que el sentido común se cree universal, hegemónico e incuestionable, y es muy difícil demostrar la parcialidad de este sentido común parcial que se muestra cómo universal. Llegando a producir un choque que hace casi imposible la comprensión entre las partes. [...] Por ello toda la producción de sentido de la cultura es un campo de batalla básico, en la medida que se crea cultura se cuestiona los límites del discurso hegemónico o se fortalecen” Diario:9Jun2016(SB).

El último elemento del aspecto comunicativo en estos espacios es el diálogo, que es la herramienta clave para la acción colectiva. Se da una relación clara entre la toma de decisiones y el diálogo; por eso cuando se pregunta por el funcionamiento de estos espacios siempre se hace referencia a la asamblea como lugar de coordinación a través del debate, a través de la argumentación y la deliberación. Las asambleas y reuniones son el lugar donde expresar las ideas e intereses para llegar a acuerdos y consensos sobre las acciones a realizar, consensos que se plantean como proceso y no tanto como algo finalizado y cerrado.

"Pues es todo a base de consenso, tú lo sabes, a base de consenso y a base de acuerdos, [...] nos ponemos de acuerdo en todo, se somete a consenso, se planea todo, todo se debate y ya está y se llega a un consenso y se llega a un acuerdo de todas las cosas que se tienen que hacer" Entrevista:77 ${ }^{\wedge}(\mathrm{EVA} \mid \mathrm{ML})$.

\section{c) Aprendizaje y práctica ciudadana}

La implicación en procesos de transformación social como los que se han descrito es en sí mismo una experiencia de aprendizaje y éste a su vez es una herramienta de transformación social (entendido como comprehensión y construcción intersubjetiva de la realidad; Mata, 2011). Resulta interesante recorrer la experiencia de incorporación de las personas a estos espacios, que en realidad no dista mucho de nuestra propia experiencia durante el trabajo de campo. Se inicia a través de la escucha y la observación con el objetivo de ir incorporando los significados grupales $\mathrm{y}$ habilidades personales que permitirán aumentar la participación en el grupo:

"Me meto en EVA, voy en septiembre, no en octubre de hace dos años, voy a Intermediae y bueno pues veo los, toda esa energía y todas esas ideas, primero, no sabía como se participaba en asamblea, ni hablaba ¿sabes? Estuve hasta que hablé pues igual me tiré dos meses o tres meses que yo iba allí, escuchaba" Entrevista:36ð̂(EVA|ML).

El proceso es diverso y único para cada persona, pues fluctúa de manera diferente entre la participación pasiva en actividades y/o asambleas a la participación activa en actividades y asambleas. Pero para muchas personas la forma de ir socializándose y aprendiendo a participar en estos grupos para modificar esa postura inicial de observación, es a través de la acción:

"Al principio, con todo lo que hablo (risa), era escuchar, escuchar, escuchar y ver un poco, aprender de la gente que llevaba mucho tiempo en el barrio, que conocía. A mí me llamaba muchísimo la atención las cosas que sabían del barrio, los datos que se manejaban con, con la facilidad y con la precisión que se manejaban, todo eso al principio me aturullaba también porque no, no sabía si, si iba a poder contribuir a algo. Pero yo vengo aquí y a ver, y si hay que hacer algo, pues no sé, si hay que preparar cualquier cosa o cualquier actividad pues la preparo, entonces por esa parte de la acción, para mí era más fácil, más fácil entrar” Entrevista:42 + (EVA).

Además este proceso de socialización y aprendizaje permite resolver un problema detectado para la acción colectiva realizada desde la horizontalidad y la equidad, 
Aguado, Teresa; Melero, Héctor S., \& Gil-Jaurena, Inés (2018). Espacios y prácticas de participación ciudadana. Propuestas educativas desde una mirada intercultural. RELIEVE, 24(2), art. M3. doi: http://doi.org/10.7203/relieve.24.2.13194

problema que se relaciona con el nivel de experiencia previa en procesos de participación y en este tipo de espacios. En otras palabras, el aprendizaje permite eliminar las diferencias creadas por las distintas competencias participativas previas:

"Entonces bueno, pues luego a nivel, creo yo que hay otro tipo de segregaciones, que tienen más que ver más con la experiencia dentro de estos movimientos, entonces la gente que no tiene mucha experiencia se cohíbe, sea hombre o mujer" Entrevista:60 9 (EVA|RadAr).

La idea de experimentación se relaciona con el aprendizaje a través de la puesta en práctica de nuevas ideas y experiencias para luego reflexionar de los errores y aciertos para sacar conclusiones que orienten las futuras acciones y experimentaciones:

"Para mí ha habido muchos errores que hemos cometido, pero es lo que te digo, es que tenemos que errar muchas veces, para poder tener experiencia y para poder saber, oye mira, es que la otra vez nos pasó esto, pues ahora tenemos que hacer esto otro porque no queremos que nos vuelva a pasar, de todo se aprende” Entrevista:38+(EVA)

Esta idea de reflexión de la acción y la experiencia, esta idea de praxis, es también compartida por los espacios. Por lo que, además de los momentos espontáneos y no planificados como el que acabo de ejemplificar, la reflexión de la acción se planifica y organiza. Durante toda mi estancia en el campo, EVA, que era un grupo grande y por lo tanto no podía realizar reflexiones profundas y compartidas en momentos informales que implicaran a la mayoría de los integrantes (cosa que sí pasaba en otros espacios más pequeños), organizaba periódicamente encuentros, denominados "metafísica", de reflexión sobre las acciones, experiencias y conflictos, sobre su propia práctica en definitiva. Estas reuniones de "la metafísica” solían durar todo un día e incluso un fin de semana y su principal objetivo era la reflexión conjunta sobre sí mismos. De hecho, en el día a día cuando algún tema surgía en una asamblea pero requería una reflexión profunda que acapararía toda la reunión, se aplazaba para abordarlo en estos momentos de "metafísica”. Estos encuentros eran valorados muy positivamente como expresa esta informante. Además similares encuentros organizados de reflexión se realizan en otros espacios ciudadanos de manera periódica:

"Yo creo que es un momento que, que es rico, es muy rico, y además creo que es en el único espacio, a pesar de todo, donde se está hablando, se están hablando cosas muy de dentro, muy personal, eso no se da en todos los espacio ¿eh?” Entrevista:62 + (EVA).

"En Esto es una Plaza una vez al año se reúnen para hacer unas jornadas de reflexión para decidir y pensar lo que se quiere, incluido la finalidad y en profundidad, ayuda a que a lo largo del año las pequeñas decisiones que se tomen sean acordes a esas finalidades" Diario:28Ene2016(EVA).

En relación con la reflexión sobre la acción, hay que decir que en el espacio institucional, el Proceso del Mercado (ML), no se realizó en ningún momento. Faltaron espacios de debate y reflexión, y faltó por tanto aprendizaje, es decir, faltó reflexionar sobre lo realizado para, a través de la crítica, poder generar aprendizajes. De hecho, esta idea de aprendizaje que sí era un discurso exculpatorio de los posibles errores en este tipo de procesos institucionales, llevaba inevitablemente a la idea y reclamación de la "evaluación”, entendida como ejercicio de reflexión y valoración, del propio proceso, evaluación que sin embargo no fue realizada.

Aunque los procesos de aprendizaje e incorporación a estos espacios son diversos y únicos para cada persona, hay cierta pauta que se repite más habitualmente. Lo primero es que el aprendizaje supone pasar de actitudes más pasivas a otras más activas, y se diferencia entre estas actitudes en los espacios de debate y toma de decisión (como las asambleas) y en los momentos de más acción (como las actividades). Así, suele desarrollarse una actitud más activa primero en las actividades, es decir, parece más fácil incorporarse plenamente en la acción y da más "reparo" hacerlo en los debates y toma de decisiones. Aunque esto también depende de la experiencia previa. 
Aguado, Teresa; Melero, Héctor S., \& Gil-Jaurena, Inés (2018). Espacios y prácticas de participación ciudadana. Propuestas educativas desde una mirada intercultural. RELIEVE, 24(2), art. M3. doi: http://doi.org/10.7203/relieve.24.2.13194

Otro de los aspectos que resulta más interesante tiene que ver con la posibilidad del ejercicio práctico en distintos roles $\mathrm{y}$ funciones en las diversas acciones $y$ actividades que realizan los espacios, lo que supone un aprendizaje práctico de dichos roles y funciones. Además este ejercicio práctico se hace con el soporte del resto de personas que también participa, lo que supone un apoyo mutuo que da confianza y seguridad así como permite y facilita dicha experimentación práctica.

"pero no me digas como tengo que hacerlo, o sea ayúdame y guíame, me puedes dar un consejo, pero déjame que yo me las apañe porque creo que lo bonito de EVA es que mucha gente está perdiendo el miedo a incluso enfrentarse a organizar cosas, que eso es lo bueno, ese es el empoderamiento, ahí es donde veo el empoderamiento y el poder de EVA, el aprendizaje" Entrevista:44우(EVA|RadAr|ML)

La experimentación en sí misma también es un principio de aprendizaje de estos espacios; la idea de experimentar a través de la experiencia, de poder probar, y de aprender de los errores y aciertos, supone entender la propia acción como un aprendizaje. De hecho esta idea se relaciona con los tres elementos definidos en el modelo (Melero, 2018): la experiencia práctica implica la participación activa, la experimentación es la puesta en práctica de propuestas prefigurativas encaminadas a la transformación social, y la evaluación de los errores y aciertos supone aplicar la capacidad crítica sobre los resultados de la experimentación desarrollada.

Otro aspecto que hay que destacar es la importancia del pensamiento crítico como potenciador de la creatividad. Acostumbrarse a poner en cuestión los "sentidos comunes", el intentar mirar más allá de los marcos de análisis e interpretación establecidos, no solo permite encontrar formas más justas $\mathrm{y}$ democráticas de actuación y cuestionar los mecanismos de opresión y desigualdad, además implica un continuo aprendizaje porque supone crear nuevas formas de mirar el mundo.

Por último, hay que destacar la idea de conflicto. Este parece inevitable en espacios que buscan la participación y la inclusión de la diversidad, ya que esto implica el conflicto entre los distintos puntos de vista. Ahora bien, si se han construido espacios seguros para el debate sincero y abierto, bajo las premisas del cuidado del otro y la búsqueda del entendimiento por la escucha activa $y$ creativa, el conflicto no es un problema sino una oportunidad de aprendizaje. Por el contrario, si no se han construido estos espacios, el conflicto no dejará de existir, sino que sus resultados serán empobrecedores. Tanto porque suele producir el abandono de alguna de las personas en conflicto, como porque impiden el aprendizaje asociado al afrontamiento y resolución del propio conflicto.

“ Un cierto intentar establecer una paz y un no historias, tal y cual, y joder, es que yo creo que no es eso, o sea, porque eso es entender el conflicto como un problema y, otra cosa es cómo se verbalice el conflicto y cómo se trate, etcétera, etcétera, que eso es diferente ¿no? Pero joder el conflicto es que es la base del movimiento" Entrevista:46 ${ }^{\lambda}$ (EVA).

\section{Propuestas educativas}

Como se ha indicado al inicio de este documento, la finalidad del estudio ha sido formular propuestas educativas desde una mirada intercultural a partir del análisis de lo que sucede en espacios de participación ciudadana en la ciudad de Madrid. De esto damos cuenta en este apartado final.

La importancia de estas aportaciones se deriva de nuestra responsabilidad como investigadores y como formadores de educadores sociales, maestros, profesores $\mathrm{y}$ otros profesionales de la pedagogía. Nuestra aspiración es que los resultados de la investigación contribuyan a mejorar la formación de estos profesionales en lo que se refiere al ejercicio y práctica de la ciudadanía en contextos sociales diversos. Por ello, se formulan una serie de propuestas muy específicas orientadas a dos audiencias diferentes (Melero, 2018):

a) las propuestas educativas para profesionales de la educación, entendidos 
Aguado, Teresa; Melero, Héctor S., \& Gil-Jaurena, Inés (2018). Espacios y prácticas de participación ciudadana. Propuestas educativas desde una mirada intercultural. RELIEVE, 24(2), art. M3. doi: http://doi.org/10.7203/relieve.24.2.13194

como cualquier persona dedicada al ejercicio de la acción educativa;

b) las propuestas pensadas para mejorar la acción educativa en los propios espacios ciudadanos.

\section{a) Propuestas educativas para profesionales de la educación:}

- Contextualiza tu acción.

El aprendizaje ciudadano es parte de la praxis situada del ejercicio del mismo, con lo cual cualquier propuesta educativa planteada debe tener en cuenta la realidad concreta en la que se realiza y estar conectada con ella.

- Recuerda que actúas en lo individual, grupal y comunitario.

Los cambios personales producen cambios en el grupo de aprendizaje, pero a la vez los cambios en el grupo producen cambios en sus integrantes. La praxis ciudadana es producto de la acción colectiva, por lo que el trabajo cooperativo y grupal es imprescindible para su aprendizaje

- Trabaja en red y colabora.

Implica la conexión con otros profesionales de la educación comprometidos con el aprendizaje ciudadano, y con espacios ciudadanos críticos, participativos y transformadores.

- Democratiza tu espacio educativo.

Supone aumentar la implicación en la toma de decisiones de todos los posibles agentes y generar relaciones horizontales.

- Construye espacios seguros. Practica la ética del cuidado.

Un aspecto fundamental para generar espacios de participación democrática es que la gente se sienta segura en dichos espacios; que pueda expresar sus ideas y sentimientos sin miedo a ser juzgada, disentir sin miedo a ser rechazada, que exista una preocupación compartida por todas las demás personas.

- Capacita para el diálogo.
Supone desarrollar tanto la capacidad de aprender a expresar ideas, razonarlas y encontrar, seleccionar, evaluar y utilizar la información, como la escucha activa y la empatía.

- Visibiliza la diversidad y la
heterogeneidad.

Se trata de visibilizar la diversidad no como una serie de diferencias estáticas de cada individuo, sino como una conjunción única de situaciones en continuo cambio y construcción.

- Analiza la realidad desde las situaciones de privilegio y opresión.

Ante las situaciones cercanas de desigualdad, se trata pensar en alternativas e intentar llevarlas a cabo, así como de evitarlas en el propio comportamiento de forma que se desarrolle la actitud crítica.

- Plantea objetivos transformadores.

Los procesos de aprendizaje deben pasar por el planteamiento de objetivos transformadores, siempre en relación con la finalidad de profundización democrática y aumento de la justicia social, es decir, aumentar la participación y la igualdad.

- Parte de la acción directa y reflexiona sobre ella.

El aprendizaje ciudadano es una praxis, es decir, es una acción y una reflexión continua. Por eso el aprendizaje del ejercicio ciudadano solo puede realizarse a través de acciones concretas sobre las que luego reflexionaremos, $y$ sobre reflexiones que nos lleven a la acción concreta.

- Fomenta y practica la experimentación e improvisación.

El proceso de profundización democrática es un camino por construir, por lo que hay que poder ensayar y probar distintas ideas y caminos.

- Utiliza los errores y los conflictos.

A través de los errores aprendemos tanto lo que no funciona como lo que sí, y 
mediante los conflictos abordados dialógicamente en un espacio seguro y bajo el prisma democrático de igualdad y libertad, aprendemos nuevas formas de actuar y profundizar en el ejercicio ciudadano

\section{b) Propuestas educativas para personas participantes en espacios ciudadanos}

- Sé consciente de tu poder educador: la transformación como aprendizaje.

Se enseña sobre y a través de la propia praxis ciudadana, de forma que otras personas no implicadas activamente puedan tener modelos y experiencias de aprendizaje sobre la praxis ciudadana crítica, participativa y transformadora.

- Clarifica la finalidad de la transformación/aprendizaje.

Más allá de los objetivos inmediatos y propios de cada espacio, la práctica ciudadana crítica, participativa y transformadora permite el desarrollo de la democracia participativa y el aumento de la igualdad.

- Toma conciencia de la necesidad de aprendizaje y de cómo se produce.

La experiencia se consigue mediante la práctica activa, el aprendizaje es experiencial. Si se procura que todas las personas puedan tener experiencias prácticas en distintas funciones y roles, y en distintas acciones, se potenciarán los aprendizajes.

- Da valor a la improvisación y los errores.

La praxis ciudadana crítica, participativa y transformadora está en continua construcción y además requiere encontrar caminos nuevos, por lo que necesita experimentar con nuevas ideas $y$ propuestas. Para que la experimentación sirva de aprendizaje debemos entender que los errores cometidos son tan valiosos como los aciertos.

- Sistematiza la reflexión y valora la crítica.

El aprendizaje se produce por la praxis, por la integración de la acción y la reflexión. Es importante periódicamente realizar acciones de autorreflexión, centrada en la propia práctica.

- El conflicto como aprendizaje. Aprende a cuidar.

El conflicto es inevitable en cualquier grupo que pretenda ser diverso, inclusivo y además horizontal y democrático, pues el conflicto es simplemente la manifestación del encuentro de distintos puntos de vista. Por ello es una oportunidad de crear un entendimiento entre esos puntos de vista distintos. Debe darse en espacios seguros.

- Practica el consenso como proceso.

Para generar el consenso es necesario tener una pretensión de construir colectivamente, no de manipular o imponer la idea personal. La pretensión de inclusión de los distintos puntos de vista debe estar siempre presente

- Implica a educadores y evita a los expertos.

Que los espacios de participación ciudadana incorporen educadores $\mathrm{y}$ educadoras, de forma que puedan aprovechar sus conocimientos para la puesta en práctica de estas y otras propuestas de aprendizaje; no como "expertos" en educación, sino como otro participante más que, como el resto, aporta su experiencia y conocimiento al común.

Como decíamos al comienzo del artículo, la finalidad del estudio presentado ha sido analizar, desde una mirada intercultural, lo que sucede en los espacios de participación ciudadana con objeto de formular propuestas educativas para el aprendizaje de la ciudadanía activa desde un enfoque intercultural”. En este último apartado de conclusiones hemos explicitado estas propuestas dirigidas a educadores y maestros. No menos importantes son las recomendaciones a quienes nos dedicamos, desde la universidad, a la formación de educadores sociales y maestros o profesores de diferentes niveles educativos. Entre otras, destacamos la necesidad de asumir la 
Aguado, Teresa; Melero, Héctor S., \& Gil-Jaurena, Inés (2018). Espacios y prácticas de participación ciudadana. Propuestas educativas desde una mirada intercultural. RELIEVE, 24(2), art. M3. doi: http://doi.org/10.7203/relieve.24.2.13194

complejidad del mundo social y el reconocimiento de la diversidad humana como normalidad; la de formar en teoría democrática y en escuelas de pensamiento crítico; el alfabetizar informacionalmente; la práctica de la reflexión y la deliberación; el uso de para actuar con grupos diversos; el uso el diálogo como instrumento en la toma de decisiones; la aplicación de técnicas y metodologías participativas; no eludir las situaciones en las que se manifiesta el conflicto; $y$, el tener en cuenta nuestras propias experiencias y saberes en el proceso de aprender y ejercer la ciudadanía de forma crítica y transformadora.

\section{Referencias}

Abdallah-Pretceille, M. (2001). La educación Intercultural. Barcelona: Idea Books.

Abdallah-Pretceille, M. (2006). Lo intercultural como paradigma para pensar la diversidad. En Conferencia Internacional de Educación Intercultural. Formación del profesorado y práctica escolar. Madrid: Grupo Inter. UNED. Consultado en http://www2.uned.es/congreso-intereducacion-intercultural/inicio_espanol.htm

Aguado, T. (2009). El enfoque intercultural como metáfora de la diversidad en educación. En T. Aguado \& M. del Olmo (Eds.), Educación Intercultural perspectivas y propuestas (pp. 13-27). Madrid: Ramón Areces.

Aguado, T. (2016). Educación intercultural para la equidad y la justicia social. Revista Convives, 14, 5-12.

Aguado, T., Ballesteros, B., Mata, P., \& Sánchez-Melero, H. (2013). Aprendizaje de la ciudadanía activa: propuestas educativas. Actas del XVI Congreso Nacional y II Internacional de Modelos de Investigación Educativa de AIDIPE, Alicante, 4-6 septiembre 2013. (pp. 35-42).

Banks, J. A. (2008). Diversity, Group Identity, and Citizenship Education in a Global Age. Educational Researcher, 37(3), 129-139.

doi: https://doi.org/dx.doi.org/10.3102/0013189 X08317501
Cabrera, F. A. (2002). Qué educación para qué ciudadanía. En E. Soriano (Ed.), Interculturalidad: fundamentos, programas y evaluación (pp. 83-129). Madrid: La Muralla.

Carr, P. R., Pluim, G., \& Howard, L. (2014). Linking Global Citizenship Education and Education for Democracy through Social Justice: What can we learn from the perspectives of teacher-education candidates? Journal of Global Citizenship and Equity Education, 4(1), 1-21. Consultado en http://journals.sfu.ca/jgcee/index.php/jgcee/a $\underline{\text { rticle/view/119 }}$

Castells, M. (2009). Comunicación y Poder. Madrid: Alianza Editorial.

Castells, M. (2012). Redes de indignación y esperanza: los movimientos sociales en la era internet. Madrid: Alianza Editorial.

Castells, M. (2017). Ruptura. La crisis de la democracia liberal. Madrid: Alianza Editorial.

CNESS (2016). L'Éducation pour la citoyanneté. Paris: Conseil National d'évaluation du système scolaire.

Del Olmo, M. (2008). El trabajo de campo etnográfico. Una introducción para los que no lo han hecho nunca. En J. A. Téllez (Ed.), Educación Intercultural. Miradas Multidiciplinares (pp. 83-96). Madrid: CIDE/La Catarata.

Del Olmo, M., \& Osuna, C. (2014). Introducción a la investigación etnográfica. En B. Ballesteros (Ed.), Taller de Investigación Cualitativa (pp. 48-76). Madrid: UNED.

Enzensberger, H. M. (2012). El gentil monstruo de Bruselas o Europa bajo tutela. Barcelona: Editorial Anagrama.

Estévez Araujo, J. A. (2013). Crisis de la democracia en Europa. Oxímora Revista Internacional de Ética y Política, 3, 8-22. Consultado en http://revistes.ub.edu/index.php/oximora/arti cle/view/9772

Diario Oficial de las Comunidades Europeas 
Aguado, Teresa; Melero, Héctor S., \& Gil-Jaurena, Inés (2018). Espacios y prácticas de participación ciudadana. Propuestas educativas desde una mirada intercultural. RELIEVE, 24(2), art. M3. doi: http://doi.org/10.7203/relieve.24.2.13194

(2001). La Gobernanza Europea. Un libro Blanco. COM2001 428final. Consultado en http://eur-

lex.europa.eu/LexUriServ/LexUriServ.do?ur $\mathrm{i}=\mathrm{OJ}: \mathrm{C}: 2001: 287: 0001: 0029: \mathrm{ES}: \mathrm{PDF}$

Folgueiras Bertomeu, Pilar (2008). La participación en sociedades multiculturales. Elaboración y evaluación de un programa de participación activa. RELIEVE, 14(2), art. 4. doi: https://doi.org/10.7203/relieve.14.2.4193

Freire, P. (1980). Pedagogía del Oprimido. Madrid: Siglo XXI.

Freire, P. (2012). Pedagogía de la indignación. cartas pedagógicas en un mundo revuelto. Buenos Aires: Siglo XXI.

Gil-Jaurena, I., Ballesteros, B., Mata, P., \& Sánchez-Melero, H. (2016). Ciudadanías: significados y experiencias. Aprendizajes desde la investigación. Foro de Educación, 14(20), 283-303. https://doi.org/10.14516/fde.2016.014.020.014

Gil-Jaurena, I., López-Ronda, S., \& SánchezMelero, H. (2015). Investigación sobre espacios de participación ciudadana: análisis $\mathrm{y}$ propuestas desde una perspectiva educativa. Revue Internationale Animation, Territoires at Pratiques Socioculturelles (ATPS), (8), 1-12. Consultado en http://www.atps.uqam.ca/numero/n8/pdf/AT $\underline{\text { PS_Gil-JaurenaEtAl_2015.pdf }}$

Gil-Jaurena, I., Sánchez-Melero, H., \& López-Ronda, S. (2013). La participación como clave en la investigación de espacios de aprendizaje de la ciudadanía. En S. Torío, O. García-Pérez, J. V. Peña, \& M. C. Fernández, (Coord.) (Eds.), Crisis social y Estado del Bienestar: las respuestas de la Pedagogía Social (pp. 84-88). Oviedo: Universidad de Oviedo.

Goetz, J. P., \& LeCompte, M. D. (1988). Etnografía y diseño cualitativo en investigación educativa. Madrid: Ediciones Morata.

Laval, C., \& Dardot, P. (2017). La pesadilla que no acaba nunca. El neoliberalismo contra la democracia. Barcelona: Gedisa.

Manguijón, J., \& Pac, D. (2012). 15M. Una explicación en clave sociológica. Prisma
Social. Revista de Ciencias Sociales, 8, 414$439 . \quad$ Consultado en http://www.isdfundacion.org/publicaciones/r evista/numeros/8/secciones/abierta/04-15Mexplicacion-clave-sociologica.html

Mata, P. (2011). Ciudadanía ética, crítica, participativa y transformadora: propuestas educativas desde el enfoque intercultural. UNED (Universidad Nacional de Educación a Distancia). Facultad de Educación. Consultado en http://espacio.uned.es/fez/view.php?pid=tesisuned: Educacion-Pmata

Mata, P., Ballesteros, B., \& Padilla, M. T. (2013). Ciudadanía Participativa Y Transformadora: Análisis De Discursos y Propuestas De Aprendizaje. Teoría de La Educación, 25, 49-68.

Melero, H. S. (2018). Espacios y Prácticas de Participación Ciudadana. Análisis y Propuestas Educativas desde un Enfoque Intercultural. Tesis Doctoral. Universidad Nacional de Educación a Distancia (UNED). Consultado en http://espacio.uned.es/fez/view/tesisuned:ED-Pg-

Educac-Hsanchez

Pradel, M., \& García, M. (2018). El momento de la ciudadanía: innovación social y gobernanza urbana. Madrid: Los Libros de la Catarata.

Puelles, M., \& Urzúa, R. (1996). Educación, gobernabilidad democrática y gobernabilidad de los sistemas educativos. Revista Iberoamericana de Educación, 12, 107-136. Consultado en http://rieoei.org/oeivirt/rie12a05.pdf

Rodríguez, G., Gil, J., \& García, E. (1996). Metodología de la Investigación Cualitativa. Archidona: Adiciones Aljibe.

Rodríguez López, E. (2016). La política en el ocaso de la clase media. El ciclo 15MPodemos.

https://doi.org/10.1017/CBO9781107415324 .004

Sabirón, F. (2006). Métodos de investigación etnográfica en Ciencias Sociales. Zaragoza: Mira Editores.

Santos, B. D. S. (2009). Más allá del 
Aguado, Teresa; Melero, Héctor S., \& Gil-Jaurena, Inés (2018). Espacios y prácticas de participación ciudadana. Propuestas educativas desde una mirada intercultural. RELIEVE, 24(2), art. M3. doi: http://doi.org/10.7203/relieve.24.2.13194

pensamiento abismal: de las líneas globales a una ecología de saberes. En L. Tapia Mealla \& B. de S. Santos (coord.) (Eds.), Pluralismo epistemológico (pp. 31-66). La Paz. Consultado en http://biblioteca.clacso.edu.ar/ar/libros/coedi cion/olive/05santos.pdf

Soriano-Ayala, Encarnación \& GonzálezJiménez, Antonio J. (2010). El poder educativo de las asociaciones de inmigrantes en las escuelas multiculturales. RELIEVE, 16(1), art.3. doi: https://doi.org/10.7203/relieve.16.1.4150.

Subirats, J. (dir.) (2015). Ya nada será lo mismo: Los efectos del cambio tecnológico en la política, los partidos y el activismo juvenil. Madrid. Consultado en http://igop.uab.cat/wpcontent/uploads/2015/07/ya-nada-sera-lomismo.pdf

Taibo, C. (2011). El 15M en sesenta preguntas. Madrid. Los libros de la Catarata.

Veugelers, W. (ed.) (2011). Moral Development and Citizenship Education. Londres: Spranger Pub.

Walsh, C. (2007). Interculturalidad, colonialidad y educación. Revista Educación y Pedagogía, XIX(48), 25-36.

\begin{tabular}{|c|c|}
\hline Authors / Autores & $\begin{array}{l}\text { To know more } \\
\text { / Saber más }\end{array}$ \\
\hline Aguado, Teresa (maguado@edu.uned.es ) & ORCID \\
\hline $\begin{array}{l}\text { Catedrática de Universidad en el Departamento de Métodos de Investigación } \\
\text { y Diagnóstico en Educación I. Facultad de Educación. UNED. Su ámbito de } \\
\text { docencia e investigación son las cuestiones sobre diversidad e igualdad en }\end{array}$ & $\underline{0000-0002-8867-4450}$ \\
\hline $\begin{array}{l}\text { Su dirección postal es: Facultad de Educación. C/ Juan del Rosal, 14. 28040- } \\
\text { Madrid (España). }\end{array}$ & ResearchGate \\
\hline Melero, Héctor S. (sanchez@invi.uned.es) & ORCID \\
\hline $\begin{array}{l}\text { Doctor en Educación. Investigador en Formación (FPI-UNED 2015) en la } \\
\text { Facultad de Educación. Departamento de Métodos de Investigación y } \\
\text { Diagnostico en Educación I (MIDE I). Su dirección postal es: Facultad de } \\
\text { Educación. C/ Juan del Rosal, 14. 28040-Madrid (España). }\end{array}$ & gle \\
\hline Gil-Jaurena, Inés (inesgj@edu.uned.es) & ORCID \\
\hline $\begin{array}{l}\text { Profesora contratada doctora en el Departamento de Teoría de la Educación y } \\
\text { Pedagogía Social de la Facultad de Educación de la UNED. Editora de la } \\
\text { revista Open Praxis, publicada por el International Council for Open and } \\
\text { Distance Education - ICDE. Su dirección postal es C/ Juan del Rosal 14, } \\
\text { despacho 285. 28040-Madrid (España). }\end{array}$ & $000-0001-7045$ \\
\hline
\end{tabular}

\section{RELIEVE}

Revista ELectrónica de Investigación y $\mathbf{E V}$ aluación Educativa E-Journal of Educational Research, Assessment and Evaluation [ISSN: 1134-4032]

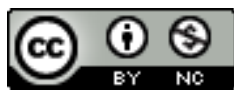

Esta obra tiene licencia de Creative Commons Reconocimiento-NoComercial 4.0 Internacional. This work is under a Creative Commons Attribution 4.0 International license. 